\title{
Action Observation Training Reduces Freezing of Gait Among Individuals with Parkinson's Disease: A Systematic Review
}

Ivan Iton

Utica College, ijiton@utica.edu

Morgan Phillips

Utica College, mcphilli@utica.edu

Kylie Reardon

Utica College, kdreardo@utica.edu

Katlyn Scarpinella

Utica College, kascarpi@utica.edu

Eileen Woodcock

Utica College, emwoodco@utica.edu

See next page for additional authors

Follow this and additional works at: https://nsuworks.nova.edu/ijahsp

Part of the Physical Therapy Commons, and the Physiotherapy Commons

\section{Recommended Citation}

Iton I, Phillips M, Reardon K, Scarpinella K, Woodcock E, Smith JM. Action Observation Training Reduces Freezing of Gait Among Individuals with Parkinson's Disease: A Systematic Review. The Internet Journal of Allied Health Sciences and Practice. 2022 Jan 03;20(1), Article 6.

This Systematic Review is brought to you for free and open access by the College of Health Care Sciences at NSUWorks. It has been accepted for inclusion in Internet Journal of Allied Health Sciences and Practice by an authorized editor of NSUWorks. For more information, please contact nsuworks@nova.edu. 


\title{
Action Observation Training Reduces Freezing of Gait Among Individuals with Parkinson's Disease: A Systematic Review
}

\begin{abstract}
Purpose: Recent evidence suggested action observation training (AOT) may benefit individuals with Parkinson's disease (PD) experiencing freezing of gait (FoG). The purpose of this study was to determine if AOT can effectively decrease FoG among people with PD. Method: This review followed PRISMA guidelines and was registered a priori with PROSPERO. The databases PubMed, CINAHL, Cochrane Database of Systematic Reviews, PEDro and PROSPERO were searched. Inclusion criteria were randomized controlled studies, an intervention with AOT, adult subjects with PD, published in a journal, and written in English. Study quality was evaluated with the APTA Critical Appraisal Tool for Experimental Intervention Studies (CAT-EI), and level of the evidence with the Oxford Centre for Evidence-based Medicine - Levels of Evidence for Therapy/Prevention Studies Rating Scale. Results: Five studies met inclusion criteria and yielded 145 participants with a mean age of 69.5 years. Most evidence was rated as acceptable quality, one study rated as low quality, and the level of evidence was high. The studies had participants undergo approximately one hour of intervention, typically two or three times a week for a period of four to eight weeks. Intervention with AOT resulted in significant improvements for the outcome measures of the Timed Up and Go Test (TUG), 10 Meter Walk Test (10MWT), self-reported FoG Questionnaire, self-reported New FoG Questionnaire, and FoG score on the Unified PD Rating Scale. Conclusions: Based on an acceptable level of evidence, there was a significant effect from the intervention of AOT for decreasing FoG among people with PD. Recommendation is that AOT effectively reduces FoG among people with PD and is a feasible and safe intervention.
\end{abstract}

\section{Author Bio(s)}

Ivan Iton, SPT. Ivan is a graduate student in the Doctor of Physical Therapy Program at Utica College, Utica, NY.

Morgan Phillips, SPT. Morgan is a graduate student in the Doctor of Physical Therapy Program at Utica College, Utica, NY.

Kylie Reardon, SPT. Kylie is a graduate student in the Doctor of Physical Therapy Program at Utica College, Utica, NY.

Katlyn Scarpinella, SPT. Katlyn is a graduate student in the Doctor of Physical Therapy Program at Utica College, Utica, NY.

Eileen Woodcock, SPT. Eileen is a graduate student in the Doctor of Physical Therapy Program at Utica College, Utica, NY.

James M. Smith, PT, DPT, MA. James is a Professor of Physical Therapy at Utica College, Utica, NY.

\section{Acknowledgements}

Acknowledgements: The authors are grateful to Janis Winn, MLS and Arlene Lundquist, PhD for consultation with this study

Authors

Ivan Iton, Morgan Phillips, Kylie Reardon, Katlyn Scarpinella, Eileen Woodcock, and James M. Smith 


\title{
1IJAHSP ${ }^{m}$ \\ The Internet Joumnal of Allied Health Sciences and Practice \\ Dedicated to allied health professional practice and education \\ Vol. 20 No. 1 ISSN 1540-580X
}

\section{Action Observation Training Reduces Freezing of Gait Among Individuals with Parkinson's Disease: A Systematic Review}

\author{
Ivan Iton \\ Morgan Phillips \\ Kylie Reardon \\ Katlyn Scarpinella \\ Eileen Woodcock \\ James M. Smith \\ Utica College \\ United States
}

\begin{abstract}
Purpose: Recent evidence suggested action observation training (AOT) may benefit individuals with Parkinson's disease (PD) experiencing freezing of gait (FoG). The purpose of this study was to determine if AOT can effectively decrease FoG among people with PD. Method: This review followed PRISMA guidelines and was registered a priori with PROSPERO. The databases PubMed, CINAHL, Cochrane Database of Systematic Reviews, PEDro and PROSPERO were searched. Inclusion criteria were randomized controlled studies, an intervention with AOT, adult subjects with PD, published in a journal, and written in English. Study quality was evaluated with the APTA Critical Appraisal Tool for Experimental Intervention Studies (CAT-EI), and level of the evidence with the Oxford Centre for Evidence-based Medicine - Levels of Evidence for Therapy/Prevention Studies Rating Scale. Results: Five studies met inclusion criteria and yielded 145 participants with a mean age of 69.5 years. Most evidence was rated as acceptable quality, one study rated as low quality, and the level of evidence was high. The studies had participants undergo approximately one hour of intervention, typically two or three times a week for a period of four to eight weeks. Intervention with AOT resulted in significant improvements for the outcome measures of the Timed Up and Go Test (TUG), 10 Meter Walk Test (10MWT), selfreported FoG Questionnaire, self-reported New FoG Questionnaire, and FoG score on the Unified PD Rating Scale. Conclusions: Based on an acceptable level of evidence, there was a significant effect from the intervention of AOT for decreasing FoG among people with PD. Recommendation is that AOT effectively reduces FoG among people with PD and is a feasible and safe intervention.
\end{abstract}

Keywords: Parkinson's disease, freezing of gait, action observation training, systematic review 


\section{INTRODUCTION}

Parkinson's disease (PD) may cause freezing of gait (FoG), an episodic inability to generate effective stepping. FoG has been associated with alterations in cortico-basal ganglia information processing and the disruption of cortical and cerebellar brainstem connections. ${ }^{1}$ FoG is more likely to be found among individuals with PD for a longer duration, those with higher motor severity, postural instability and gait disturbance. ${ }^{2} \mathrm{FoG}$ may result in increased falls, activity limitations and participation restrictions that reduce quality of life. ${ }^{3}$

Action Observation Training (AOT) is a rehabilitation intervention to help subjects improve performance with motor tasks. AOT is based on the observation of the action of others with the intention to perform that specific motor task. ${ }^{4}$ The technique typically requires the subject to carefully observe a video demonstrating actions that the subject then executes and practices. ${ }^{5}$ Agosta et al proposed that AOT facilitated motor learning consolidation in a mechanism best described as a "top-down" theory of rehabilitation. ${ }^{6}$ It has also been proposed that AOT activates mirror neurons, or the observation-execution matching system, in the frontal and parietal lobes, which in return assists in activating areas of the brain responsible for executing the desired movement. ${ }^{7}$ This effect may have the capacity to be harnessed for rehabilitation by involving higher-level networks that impact peripheral circuits, e.g. central movement planning areas, motor areas and the engagement of peripheral structures. ${ }^{8}$

Caligiore et al proposed that AOT may benefit people with PD by improving motor abilities. ${ }^{7}$ FoG has the effect of reducing activity and participation among individuals with PD, and AOT presents with the capacity for reducing or ameliorating the effects of FoG. ${ }^{9}$ The purpose of this systematic review is to ascertain whether AOT is effective at reducing FoG among individuals with PD.

\section{METHODS}

This systematic review followed the Preferred Reporting Items for Systematic Reviews and Meta-Analyses (PRISMA) guidelines to ensure the review was constructed in a systematic way and reduce the risk of bias within this study. ${ }^{10}$ The study was registered a priori with PROSPERO, the international prospective register of systematic reviews. ${ }^{11}$

\section{Eligibility and Search}

The inclusion criteria for this study were randomized control trials, an intervention trial which included action observation training, adult (18 years and older) subjects with PD, published in a journal, and written in English. Studies were excluded if they were abstracts or conference proceedings as these provided a low-level evidence.

Five databases were searched in February 2020; those were PubMed, CINAHL, Cochrane Database of Systematic Reviews, PEDro, and PROSPERO. The search strategies were developed in consultation with a research librarian to utilize the appropriate search terms unique to each database. The titles and abstracts of the studies that were retrieved from this search were then reviewed independently by two authors to identify studies that could potentially meet the inclusion criteria. If there was disagreement among these two authors, a third author reviewed the study to establish eligibility for inclusion. Studies identified as potentially eligible based on the title and abstracts were retrieved as full text articles. The full text was reviewed and eligibility was assessed by two authors. If there was disagreement among the two authors, a third author reviewed the article and resolved the disagreement.

\section{Methodological Quality}

The Critical Appraisal Tool for Experimental Intervention (CAT-EI) has been endorsed for use with physical therapy interventions and was utilized to assess the risks for bias in individual studies. ${ }^{12}$ The quality evaluation-overall design component of the CAT-EI contained 20 criteria that were assessed as present or absent within each study, and the resultant score was used to assign the overall quality rating grade. Each study was ranked as having high, acceptable, low or unacceptable quality based on the critical appraisal tally. Thresholds have not been defined for those rankings, so we prospectively assigned the rankings as high quality (ie, low risk of bias) for scores $16-20$, acceptable quality for scores $12-15$, low quality for scores $7-11$, and unacceptable quality (ie, high risk of bias) for scores $0-6$. All authors participated in training with applying the CAT-El to ensure consistent interpretation of each item. Practice with the tool continued until there was consistency among the authors in the interpretation of all items and scoring. Each study was evaluated for its risks for bias using the CAT-El by two authors who scored independently. If there was disagreement among these authors, a third author resolved the disagreement.

The level of the evidence in individual studies was evaluated with the Oxford Centre for Evidence-based Medicine - Levels of Evidence for Therapy/Prevention Studies Rating Scale (OCEM), with ratings based on a score ranging from a high of 1 (systematic review) to a low of 5 (expert opinion). ${ }^{13}$ 


\section{Data Management}

A data table was developed prior to the data extraction, and the authors identified items deemed as possibly relevant to the study. The full text article of each study was then independently reviewed by two authors. Each author extracted the data and recorded it in the data table independently. After data extraction was performed, the authors compared data. If the data did not have absolute agreement, a third author was used to resolve the disagreement.

The included studies used the Timed Up and Go (TUG) test, self-reported FoG questionnaire, self-reported New FoG Questionnaire, 10 Meter Walk Test (10MWT) and Freezing of Gait score on the Unified PD Rating Scale (UPDRS) to reveal changes in activity and participation. The TUG test measures the ability to rise from a chair, walk 3 meters, turn, walk 3 meters and then sit back in the chair. This allows the examiner to measure the time to perform this functional activity, and among some populations the risk for falls can be predicted. ${ }^{14}$ Individuals that do not have impairments can complete this in an average of less than 10 seconds, while individuals who have a neurological disease, such as PD, may have difficulty completing this in 30 seconds, placing them in the range for an elevated risk of falls. ${ }^{14}$ The TUG test is a test that is easily administered and is often used for individuals with $\mathrm{PD}$, and has a minimal detectable change (MDC) value of 3.5 seconds. ${ }^{15}$

The FoG questionnaire (FoG-Q) is a 16-item form that the subject, family members or caregiver can fill out to gain information about the unpredictable periods of FoG. ${ }^{16}$ The questions identify falls, festination of gait, turning to change direction, freezing, and the effects on daily living and the length of FoG when it occurs. The FoG was revised to The New Freezing of Gait- Questionnaire (NFoG-Q), which is a 9-item form, and was developed to address the limitations of the original FoG questionnaire. ${ }^{17}$ Both questionnaires assess the patient when they are in a state of being "off" and being "on." The "off" state is prior to the patient taking antiparkinsonian medication and "on" is when the medication is in effect. ${ }^{17}$ The MDC for the FoG and the N-FoG questionnaire is $9.98 .{ }^{18}$

Typically, the timed 10MWT is completed in two trials at a comfortable walking speed followed by 2 trials at a fast walking speed, and the times are then combined and averaged to measure a subject's comfortable and fast walking speeds. This test is completed by measuring out 10 meters and adding marks for the 2- and 8-meter point. Those two points are used to initiate the measurement for the start and end of the timing. ${ }^{19}$ The MDC for the 10MWT has been established for subjects with PD who walk at a comfortable pace as $0.22 \mathrm{~m} / \mathrm{s}$ and at a fast pace as $0.23 \mathrm{~m} / \mathrm{s} .{ }^{20}$

The UPDRS is a scale that is used to quantify the symptoms commonly associated with PD. FoG was a relevant component of the UPDRS to this systematic review as it quantifies the severity of FoG in patients with PD. The patient is instructed to walk at least 10 meters and turn around and return to the examiner. The examiner observes for hesitation and stuttering movements especially when turning and reaching the end of the task. A score of zero, being the absence of FoG, to four, freezing multiple times during the task, is assigned to the patient.22

\section{RESULTS}

PubMed was searched on March 2, 2020, with the search terms "Parkinson* AND action observation training AND AO", 80 articles were identified. CINHAL was searched on 22 February 2020 with the search terms "Parkinson's disease AND training AND freezing", 48 articles were identified. Cochrane Database of Systematic Reviews was searched on 18 February 2020 with the search terms "action observation" Parkinson* freez AND gait", 11 articles were identified. PEDro was searched on February 18, 2020, with the search terms "action observation" AND "freezing", four articles were identified. PROSPERO was searched on February 22, 2020, with the search terms "parkinson* AND action observation", six articles identified. Some terms were searched in a truncated form to optimize the performance of the respective search engines. Collectively, the database search identified 149 articles. This list of articles was then screened for duplicates and nine were removed, therefore 140 articles remained.

The abstracts of these studies were screened based on the inclusion and exclusion criteria, after that 118 articles were excluded, leaving 22 articles remaining. Full text was obtained for those 22 studies for further review, following which 17 articles were excluded. Among those articles, ten were excluded due to not being a randomized control trial or not having an intervention trial with AOT, two articles were randomized control trials but did not include AOT, two did not have a control group, one was a systematic review, one was a poster presentation, and one did not comply with the definition of AOT adopted for this study. Therefore, five articles remained for inclusion in this review (Figure 1). 


\section{Identification of new studies via databases and registers}

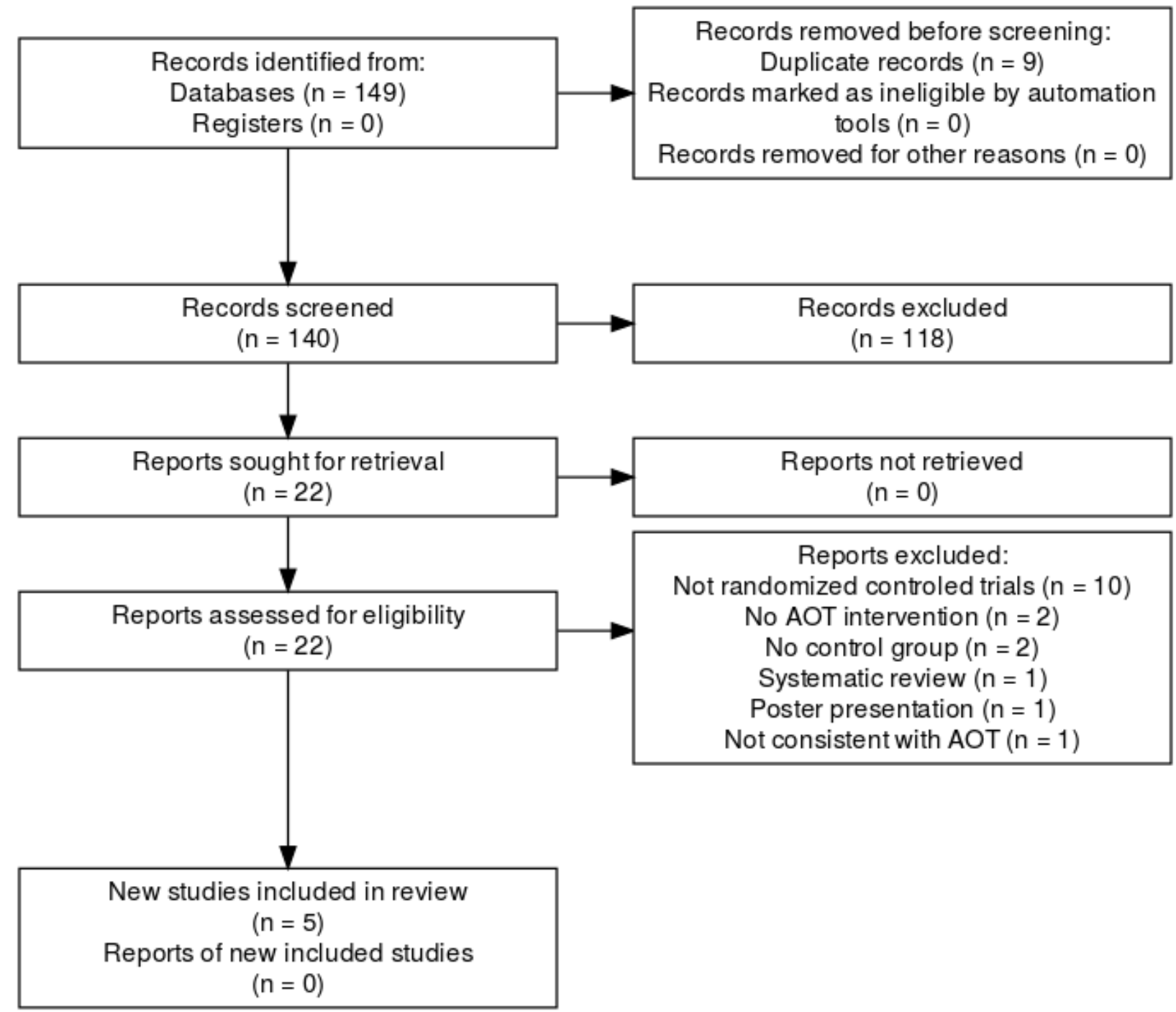

Figure 1. PRISMA Flow Diagram

\section{Methodological Quality}

The risk for bias (quality) in the studies were scored with the CAT-El. Among the five included studies, the scores ranged from a low of nine to a high of 13 (Table 1). Three studies were rated as acceptable quality, and in the Pelosin et al study (2010), the data on freezing of gait was rated as acceptable. $6,21,23,24$ One study was rated as low quality, and in the Pelosin et al study (2010), the data on the TUG test and 10MWT were rated as low quality. ${ }^{9,24}$

The OCEM has scores ranging from a high of one to a low of five. Subcategories include individual randomized controlled trials with narrow confidence intervals, rated as $1 \mathrm{~b}$, and individual cohort study including low quality randomized controlled trials $2 \mathrm{~b} .{ }^{13}$ Application of the OCEM revealed three studies had an evidence level $1 \mathrm{~b}$ and two studies had an evidence level $2 \mathrm{~b}$. 
Table 1. Quality of Studies: Level of Evidence and Risk of Bias

\begin{tabular}{|c|c|c|c|}
\hline Study & CAT-EI Score & Level of Quality & Level of Evidence \\
\hline Mezzarobba et al., $2018^{23}$ & 13 & Acceptable & $1 b$ \\
\hline Pelosin et al., $2018^{9}$ & 9 & Low & $1 b$ \\
\hline Agosta et al., $2017^{6}$ & 14 & Acceptable & $1 b$ \\
\hline Giorgi et al., $2018^{21}$ & 13 & Acceptable & $2 b$ \\
\hline Pelosin et al., $2010(10 \mathrm{MWT})^{24}$ & 11 & Low & $2 b$ \\
\hline Pelosin et al., 2010 (TUG) ${ }^{24}$ & 11 & Low & $2 b$ \\
\hline Pelosin et al., 2010 (FoG) ${ }^{24}$ & 13 & Acceptable & $2 b$ \\
\hline
\end{tabular}

CAT-El (Critical Appraisal Tool for Experimental Intervention Studies). Level of Evidence based on the Oxford Centre for Evidencebased Medicine - Levels of Evidence for Therapy/Prevention Studies Rating Scale (OCEM), scores range from a high of 1 to a low of 5. 1b: Individual randomized controlled trials with narrow confidence intervals. $2 \mathrm{~b}$ : Individual cohort study including low quality randomized controlled trials. 10MWT: 10 Meter Walk Test, TUG: Timed Up and Go, FoG: Freezing of Gait.

\section{Participants and Interventions}

Collectively, the five studies yielded 145 participants, with a mean age of 69.5 years, who received an intervention of AOT. The participants' Hoehn \& Yahr Stages ranged from ratings of one to four. Giorgi et al had participants complete individual one-hour treatment sessions over the course of four weeks. The videos utilized in this study included videos of bilateral movements of the upper limb (18 videos), ambulation on different surfaces and stairs (2 videos), and movement of the lower limb (2 videos). The upper limb videos shown in the first 30 minutes were approximately 40 seconds in length including tasks such as picking pills from a blister pack or taking a sheet of paper and wrapping a box. The lower limb videos were approximately 100 seconds in length, shown for a total of 30 minutes and included tasks such as stepping over obstacles, and ascending and descending stairs.

There were three training sessions per week. During these sessions the intervention cohort performed 30 minutes of treatments that were applied to the upper extremities and 30 minutes were applied to the lower extremities. The videos were 40-100 seconds long with no audio, and after each observed video, the task was performed one to three times. ${ }^{21}$ Mezzarobba et al provided individual training sessions that lasted one hour, two training sessions per week, provided over the course of eight weeks. During each training session, eight videos showing an actor performing eight different motor gestures were presented to the patient, who then tried to replicate the movements, according to modeling principles. Each video lasted 1.5 minutes, and was composed of images (from fronto-lateral perspectives) and sounds of eight specific motor gestures. The motor gestures included weight shifting, step scaling, and bilateral coordination of stepping. ${ }^{23}$

Pelosin et al used group training sessions that lasted one hour, three sessions per week, over the course of four weeks. During each session, six videos of six minutes duration were presented for a total of 24 minutes, followed by 36 minutes of the participant performing the observed movements. The videos included strategies useful in circumventing FoG. ${ }^{24}$ Another study by Pelosin et al held group training sessions that lasted 45 minutes, two training sessions per week, over the course of five weeks. During each session six videos, of six minutes duration, displayed strategies for circumventing FoG, and following that the participants were asked to execute the observed actions. During each session, two video clips were presented twice and the complexity of the actions progressed over the sessions. ${ }^{9}$ Agosta et al utilized individual training sessions that lasted one hour, three sessions per week, over the course of four weeks. During each session, two video clips (six minutes in length) which focused on circumventing FoG episodes were shown. The subjects then replicated the tasks for eight minutes. The difficulty of the tasks in the video clips progressed weekly (Table 2). ${ }^{6}$ 
Table 2: Overview

\begin{tabular}{|c|c|c|c|c|c|}
\hline Study & $\begin{array}{c}\# \\
\text { Subjects }\end{array}$ & $\begin{array}{c}\# \\
\text { Controls }\end{array}$ & $\begin{array}{l}\text { Mean Age } \\
\text { of Subjects } \\
\text { (years) }\end{array}$ & $\begin{array}{c}\text { Hoehn \& } \\
\text { Yahr Stage }\end{array}$ & AOT exposure \\
\hline $\begin{array}{l}\text { Giorgi et al, } \\
2018^{21}\end{array}$ & 16 & 8 & 65 & 3 & $\begin{array}{l}\text { Individual treatment, LE } 100 \text { second video observed twice with no } \\
\text { audio, followed by one to three trials to perform reviewed tasks, } \\
\text { treatment time } 30 \text { minutes. UE observed a } 40 \text { second video with no } \\
\text { audio, followed by one to three trials to perform given tasks, } \\
\text { treatment time } 30 \text { minutes. Video content included bilateral } \\
\text { movements of the upper limb (18 videos), ambulation on different } \\
\text { surfaces and stairs ( } 2 \text { videos), and movement of the lower limb (2 } \\
\text { videos). }\end{array}$ \\
\hline $\begin{array}{l}\text { Mezzarobba et } \\
\text { al, } 2018^{23}\end{array}$ & 22 & 10 & 73 & $1,2,3$ & $\begin{array}{l}\text { Individual treatment, eight videos observed with audio, video length } \\
90 \text { seconds, patient observed video of motor gestures, performed } \\
\text { tasks and repeated to encourage modeling process that follows } \\
\text { modeling principles. The motor gestures included weight shifting, } \\
\text { step scaling, and bilateral coordination of stepping. }\end{array}$ \\
\hline $\begin{array}{l}\text { Pelosin et al, } \\
2010^{24}\end{array}$ & 18 & 9 & 70 & 2.1 (mean) & $\begin{array}{l}\text { Group treatment, one hour in length, six-minute video observed six } \\
\text { times total of } 24 \text { minutes, followed by } 36 \text { minutes of performing } \\
\text { tasks. Videos included strategies useful in circumventing FoG. } \\
\text { Audio unspecified. }\end{array}$ \\
\hline $\begin{array}{l}\text { Pelosin et al, } \\
2018^{9}\end{array}$ & 64 & 32 & 70.4 & 2.4 (mean) & $\begin{array}{l}\text { Group treatment, six-minute videos of strategies for circumventing } \\
\text { FoG were shown, patients were asked to execute the observed } \\
\text { actions, and complexity of the actions progressed over the } \\
\text { sessions. Audio unspecified. }\end{array}$ \\
\hline $\begin{array}{l}\text { Agosta et al, } \\
2017^{6}\end{array}$ & 25 & 13 & 69 & $\begin{array}{l}\text { On: } 2.3 \\
\text { (mean) } \\
\text { Off: } 2.4 \\
\text { (mean) }\end{array}$ & $\begin{array}{l}\text { Individual treatment, one hour in length, two six-minute videos } \\
\text { observed, followed by eight minutes of performing tasks, } \\
\text { circumventing FoG. Task difficulty progressed, audio unspecified. }\end{array}$ \\
\hline Mean values & 145 & 72 & 69.48 & & \\
\hline
\end{tabular}

AOT: Action Observation Training; LE: Lower Extremity; FoG: Freezing of Gait

Consistent among these studies, the methods for interventions with AOT involved two stages. 6, 9, 21, 23, 24 The observation stage generally involved subjects observing videos of relevant motor tasks, for a given time of seconds to minutes in each of the studies. The observation stage for all five studies involved demonstrating ambulation and other motor tasks, such as pre-gait activities or upper extremity movements after observing the task. Following observation of the video the second stage involved the subjects actively repeating the motor tasks. (Table 2). $6,9,21,23,24$ Two of the studies in this systematic review involved performance of the AOT interventions within a group setting. ${ }^{9,24}$ The other three studies had their subjects perform the interventions individually (Table 3). $6,21,23$

\section{Outcomes}

Some studies evaluated the influence of antiparkinsonian medications. The "on" and "off" phase referenced the level of the dopaminergic effect of antiparkinsonian medications that patients ingested. ${ }^{22}$ Mezzarobba et al and Pelosin et al explained that the "on" phase began one hour after antiparkinsonian medication ingestion (Table 3). ${ }^{23,24}$ Three of the five included studies completed interventions on the subjects during the "on" phase (Table 3).6, 21, 23

Attrition (i.e., the loss of participants within the study) was accounted for in three of the studies and was attributed to unrelated medical events and/or personal reasons unrelated to AOT, while the other two studies reported not experiencing attrition throughout the study (Table 3). 6,9,21,22,24 
Table 3: Intervention with Action Observation Training

\begin{tabular}{|l|c|c|c|c|c|c|}
\hline \multicolumn{1}{|c|}{ Study } & $\begin{array}{c}\text { Duration of } \\
\text { AOT } \\
\text { (minutes) }\end{array}$ & $\begin{array}{c}\text { Frequency of } \\
\text { AOT (\#/week) }\end{array}$ & $\begin{array}{c}\text { Treatment } \\
\text { Duration } \\
\text { (\#weeks) }\end{array}$ & Individual or Group & $\begin{array}{c}\text { AOT During } \\
\text { Medication } \\
\text { (On/Off) }\end{array}$ & Attrition \\
\hline Giorgi et al., 201821 & 60 & 3 & 4 & $\begin{array}{c}\text { Individual sessions for } \\
\text { AOT, group sessions } \\
\text { for conventional } \\
\text { therapy }\end{array}$ & On & $0 \%$ \\
\hline $\begin{array}{l}\text { Mezzarobba et al., } \\
2018^{22}\end{array}$ & 60 & 2 & 8 & Individual & On & $8.3 \%$ \\
\hline Pelosin et al., 201024 & 60 & 3 & 4 & Group & N/A & $0 \%$ \\
\hline Pelosin et al., 20189 & 45 & 2 & 5 & Group & N/A & $4.69 \%$ \\
\hline Agosta et al., 20176 & 60 & 3 & 4 & Individual & On & $12 \%$ \\
\hline Mean values & 57 & 2.6 & 5 & & & $4.998 \%$ \\
\hline
\end{tabular}

AOT: Action Observation Training, N/A: Not Applicable

Three of the studies assessed change in the TUG scores. After the intervention, the mean times were decreased in those three studies by $14.5 \mathrm{~s}, 15.6 \mathrm{~s}$ and $12.2 \mathrm{~s}$ (Table 4), representing significant improvements. $9,21,24$ Pelosin et al evaluated the persistence of the response to AOT four weeks after completing the interventions by measuring subjects' walking performance with the TUG. ${ }^{9}$ The mean pre-intervention TUG score was $16.1 \mathrm{~s}$ and the follow up mean TUG score was $12.9 \mathrm{~s}$, representing a significant improvement (Table 4). Although Mezzeroba et al did not provide the mean values for outcome measures, the analysis provided did report that there was not significant improvement in performance on the TUG immediately after the AOT intervention, 1 month after intervention and 3 months after intervention. ${ }^{22}$

Table 4: Action Observation Training Effect on Timed Up and Go Test

\begin{tabular}{|l|c|c|c|c|c|c|}
\hline Study & $\begin{array}{l}\text { Pre-intervention } \\
\text { TUG (mean \# } \\
\text { seconds) }\end{array}$ & $\begin{array}{l}\text { Post-intervention } \\
\text { TUG (mean \# } \\
\text { seconds) }\end{array}$ & $\begin{array}{l}\text { Significant } \\
\text { Change in } \\
\text { TUG? }\end{array}$ & $\begin{array}{l}\text { Follow-up } \\
\text { TUG (\# } \\
\text { weeks) }\end{array}$ & $\begin{array}{l}\text { Follow-up TUG } \\
\text { (mean \# } \\
\text { seconds) }\end{array}$ & $\begin{array}{l}\text { Significant Change } \\
\text { in Follow-up TUG? }\end{array}$ \\
\hline Giorgi et al., 201821 & 19 & 14.5 & Yes & N/A & N/A & N/A \\
\hline Pelosin et al., 201024 & 32.5 & 15.63 & Yes & N/A & N/A & N/A \\
\hline Pelosin et al., 20189 & 16.1 & 12.2 & Yes & 4 & 12.9 & Yes \\
\hline Mean & 22.5 & 14.1 & & & & \\
\hline
\end{tabular}

TUG: Timed up and go test, N/A: Not Applicable

Three of the studies included the 10MWT as an outcome measure. ${ }^{6,9,24}$ All three studies demonstrated a significant improvement in 10MWT speed.6, 9, 24 Pelosin et al. and Agosta et al. included testing four weeks after the termination of the intervention (Table 5). 9,6 Pelosin et al. found significant improvement persisted at the four weeks follow-up, whereas Agosta et al. did not demonstrate a significant improvement after four weeks (Table 5).9,6 
Table 5: Action Observation Training Effect on 10 Meter Walk Test

\begin{tabular}{|l|c|c|c|c|c|c|}
\hline Study & $\begin{array}{l}\text { Pre-intervention } \\
\text { 10MWT (mean \# } \\
\text { seconds) }\end{array}$ & $\begin{array}{l}\text { Post-intervention } \\
\text { 10MWT (mean \# } \\
\text { seconds) }\end{array}$ & $\begin{array}{l}\text { Significant } \\
\text { Change in } \\
\text { 10MWT? }\end{array}$ & $\begin{array}{l}\text { Follow-up } \\
\text { 10MWT (\# } \\
\text { weeks) }\end{array}$ & $\begin{array}{l}\text { Follow-up } \\
\text { 10MWT (mean } \\
\text { \# seconds) }\end{array}$ & $\begin{array}{l}\text { Significant } \\
\text { Change in Follow- } \\
\text { up 10MWT? }\end{array}$ \\
\hline Pelosin et al., 201024 & 15.3 & 11.32 & Yes & N/A & N/A & N/A \\
\hline Pelosin et al., 2018 & 13.9 & 10.7 & Yes & 4 & 12.3 & Yes \\
\hline Agosta et al., 20176 & 6.56 & 6 & Yes & 4 & 6.1 & No \\
\hline
\end{tabular}

10MWT: Ten Meter Walk Test, N/A: Not Applicable

Two of the studies applied the FoG-Q., 24 Significant improvement in FoG was achieved in both of these studies indicated by this self-reported questionnaire.6, 24 Those studies also measured persistence of the effect after four weeks (Table 6).6, 24 One study demonstrated persistence of the reduction in FoG at a significant level, ${ }^{24}$ and one study did not demonstrate persistence at a significant level. ${ }^{6}$

Table 6: Action Observation Training effect on Freezing of Gait Questionnaire

\begin{tabular}{|l|l|l|l|l|l|}
\hline & $\begin{array}{l}\text { Pre-intervention } \\
\text { FoG } \\
\text { Questionnaire } \\
\text { (mean score) }\end{array}$ & $\begin{array}{l}\text { Post-intervention } \\
\text { FoG } \\
\text { Questionnaire } \\
\text { (mean score) }\end{array}$ & $\begin{array}{l}\text { Significant } \\
\text { Change in } \\
\text { FoG? }\end{array}$ & $\begin{array}{l}\text { Follow-up FoG } \\
\text { Questionnaire } \\
\text { (mean score) }\end{array}$ & $\begin{array}{l}\text { Significant Change } \\
\text { in Follow-up FoG? }\end{array}$ \\
\hline $\begin{array}{l}\text { Pelosin et al., } \\
2010^{24}\end{array}$ & 18.6 & 12.8 & Yes & 14.1 & Yes \\
\hline $\begin{array}{l}\text { Agosta et al., } \\
20176\end{array}$ & 11.7 & 9.7 & Yes & 10.2 & No \\
\hline Mean & 15.5 & 10.7 & Yes & 11.2 & \\
\hline
\end{tabular}

FoG: Freezing of Gait, N/A: Not Applicable

Two of the studies utilized the NFoG-Q. Pelosin et al provided mean values for this outcome measure; however, Mezzeroba et al did not provide values in their study but did comment on the significance of their findings (data was requested from the author and a response was not received). Both studies that included this outcome measure indicated that there was a significant improvement in the NFOG-Q. These studies also concluded that there was a persisting effect up to 3 months after the intervention in the AOT groups that was significantly improved compared to the controls. ${ }^{9,}, 24$

Table 7: Action Observation Training Effect on New Freezing of Gait Questionnaire

\begin{tabular}{|l|c|c|c|c|c|}
\hline & $\begin{array}{l}\text { Pre-intervention } \\
\text { NFoG-Q (mean } \\
\text { score) }\end{array}$ & $\begin{array}{l}\text { Post-intervention } \\
\text { NFoG-Q (mean } \\
\text { score) }\end{array}$ & $\begin{array}{l}\text { Significant } \\
\text { Change in } \\
\text { FoG? }\end{array}$ & $\begin{array}{l}\text { Follow-up NFoG-Q } \\
\text { (mean score) }\end{array}$ & $\begin{array}{l}\text { Significant Change } \\
\text { in Follow-up FoG? }\end{array}$ \\
\hline $\begin{array}{l}\text { Study } \\
\text { Pelosin et al., }\end{array}$ & 12.3 & 9.7 & Yes & 9.4 & Yes \\
\hline
\end{tabular}

Agosta et al. reported on the FoG component of the UPDRS score. ${ }^{6}$ That outcome was measured and reported both for the "on" phase and the "off" phase of the dopaminergic effect of antiparkinsonian medications. During both the "on" and "off" phases the subjects' scores improved; however, there was only a significant improvement in the scores during the "off" phase. A four-week follow-up measurement demonstrated that there was a sustained improvement on the FoG component of the UPDRS score, which was also found to be significant during the "off" phase medication period (Table 8). ${ }^{6}$ 
Table 8: Action observation training effect on the FoG component of the Unified Parkinson Disease Rating Scale

\begin{tabular}{|l|l|l|l|l|l|}
\hline & $\begin{array}{l}\text { Pre-intervention } \\
\text { UPDRS (FoG) } \\
\text { (mean score) }\end{array}$ & $\begin{array}{l}\text { Post-intervention } \\
\text { UPDRS (FoG) } \\
\text { (mean score) }\end{array}$ & $\begin{array}{l}\text { Significant } \\
\text { Change in } \\
\text { UPDRS } \\
\text { (FoG)? }\end{array}$ & $\begin{array}{l}\text { Follow-up UPDRS } \\
\text { (FoG) (mean } \\
\text { score) }\end{array}$ & $\begin{array}{l}\text { Significant Change in } \\
\text { UPDRS (FoG)? }\end{array}$ \\
\hline $\begin{array}{l}\text { Agosta et al., } \\
20176\end{array}$ & $\begin{array}{l}\text { On: } 1.33 \\
\text { Off: } 2.33\end{array}$ & $\begin{array}{l}\text { On: } 1.18 \\
\text { Off: } 1.64\end{array}$ & $\begin{array}{l}\text { On: No } \\
\text { Off: Yes }\end{array}$ & $\begin{array}{l}\text { On: } 0.89 \\
\text { Off: } 2.13\end{array}$ & $\begin{array}{l}\text { On: No } \\
\text { Off: Yes }\end{array}$ \\
\hline
\end{tabular}

UPDRS: Unified Parkinson Disease Rating Scale

\section{CONCLUSIONS \\ Implications for Practice}

AOT is a novel intervention designed to improve performance of motor tasks. This systematic review revealed AOT was an effective intervention for decreasing FoG among people with PD. Based on the included studies, AOT interventions should involve observation of videos alternated with practice of the relevant task, and collectively the sessions should involve approximately 30 minutes of video observation accompanied by 30 minutes of task practice, administered two to three times per week over the duration of a four to eight-week period. Studies that investigated AOT provided to individuals were determined to have an acceptable level of evidence, while studies that investigated AOT provided through group sessions were determined to have a low level of evidence (Table 1). Therefore, we recommend the application of AOT sessions with individual participants rather than application of AOT within group sessions. Three of the five studies were performed while the subjects were on antiparkinsonian medication and improvements in outcome measures were achieved among these participants (Table 3); therefore we endorse the intervention of AOT during the "on" phase of this medication. Additionally, subjects whose level of functioning were between levels one and three on the Hoehn and Yahr scale (identified in Table 2) achieved benefits from participating in AOT. Based on that evidence AOT is appropriate for people with PD categorized in stages one to three on the Hoehn and Yahr scale, and this evidence does not support application for those whose PD has progressed to stages four or five.

This review addressed four outcome measures (TUG, 10MWT, FoG and NFoG questionnaire, FoG score on the Unified PD Rating Scale), and AOT effectively reduced FoG across all of these measures. While there is no gold standard for measuring the impact of FoG, achieving the benefit across these different types of measures supports the efficacy of AOT as an intervention for FoG. Based on these findings, we recommend applying AOT to people who have been diagnosed with PD and experience FoG, particularly those with scores that place them between levels one and three on the Hoehn and Yahr scale. Intervention sessions with individuals should be given for one hour, three times per week over the span of two months to obtain optimal patient outcomes. To enhance treatment effects the subject should participate in AOT one hour after taking antiparkinsonism medication.

Three studies measured carryover of the response to AOT after 4 weeks. One study with low methodological quality reported persisting benefits in performance on the TUG, 10MWT and FoG questionnaire ${ }^{9}$ and another with acceptable level evidence reported persisting benefits when measured by the FoG questionnaire. ${ }^{24}$ Interpretation of these must be informed by another study, of acceptable methodological quality, that did not find persisting benefits when performance was measured with the 10MWT and the FoG questionnaire. ${ }^{6}$ Collectively, these results suggest an opportunity that benefits may persist after interventions with AOT. Future research should be designed to clarify the persisting response AOT has on FoG among people with PD, and if refresher sessions may be effectively applied to achieve the benefits.

The low levels of attrition observed suggest high levels of adherence with this intervention (Table 3). No adverse effects were observed, which showed that this was a safe intervention for a clinical setting. AOT does not require an abundant amount of expensive equipment, which also supports the feasibility of this intervention.

\section{Strengths and Limitations}

Consulting with a research librarian to determine optimal keywords when conducting our searches in databases, following a PRISMA protocol, prospectively registering with PROSPERO and accepting only controlled trials that were published in journals were strengths of our study. However, a limitation of this study was only including studies published in English.

The homogeneity of the interventions and outcome measures provided the opportunity for performing meta-analysis. However, meta-analysis was deemed inappropriate as there was an insufficient number of studies to provide for an acceptable appreciation of variance between studies. That left this study at risk for incorrect conclusions due to insufficient power. ${ }^{25,26}$ 


\section{Future Research}

For future studies we recommend evaluating the optimal dose-response relationship between AOT and reduction in FoG, and the optimal timing for initiating this intervention. The effects of training on therapist's techniques with AOT will benefit from being assessed. Additionally, the endurance of the effect of decreased freezing of gait should be examined, including whether renewed interventions with AOT will achieve better endurance.

\section{Recommendation}

AOT is a safe and feasible intervention for individuals with PD who experience FoG as it can achieve a reduction in the occurrence and severity of $\mathrm{FOG}$ episodes.

\section{REFERENCES}

1. Ortelli P, Ferrazzoli D, Cian V, Zarucchi M, Palamara G, Giobbia A, Canesi M. How cognition and motivation "freeze" the motor behavior in Parkinson's disease. Frontiers in Neuroscience. 2019;13, 1-8. https://doi.org/10.3389/fnins.2019.01302 [PMID: 31866812]

2. Prasad S, Lenka A, Stezin A, Naduthota RM, Jha M, Yadav R, Pal PK. A comparative study of early and late onset freezing of gait in Parkinson's disease. Annals of Indian Academy Of Neurology. 2018;21(4), 256-262. https://doi.org/10.4103/aian.AIAN_459_17 [PMID: 30532353]

3. Ellis T, Cavanaugh JT, Earhart GM, Ford MP, Foreman KB, Dibble LE. Which measures of physical function and motor impairment best predict quality of life in Parkinson's disease? Parkinsonism \& Related Disorders. 2011:17(9);693-697. doi: 10.1016/j.parkreldis.2011.07.004 [PMID: 21820940]

4. Gonzalez-Rosa JJ, Natali F, Tettamanti A, Cursi M, Velikova S, Comi G, Leocani L. Action observation and motor imagery in performance of complex movements: Evidence from EEG and kinematics analysis. Behavioural Brain Research. 2015;281, 290-300. doi: 10.1016/j.bbr.2014.12.016 [PMID: 25532912]

5. Buccino G. Action observation treatment: a novel tool in neurorehabilitation. Philosophical Transactions of the Royal Society. 2014; B, 369: 20130185. http://dx.doi.org/10.1098/rstb.2013.0185 [PMID: 24778380]

6. Agosta F, Gatti R, Sarasso E, Volonte MA, Canu E, Meani A, Sarro L, Copetti M, Cattrysse E, Kerckhofs E, Comi G, Falini A, Fillippi M. Brain plasticity in Parkinson's disease with freezing of gait induced by action observation training. Journal of Neurology. 2017;264, 88-101. doi: 10.1007/s00415-016-8309-7 [PMID: 27778161]

7. Caligiore D, Mustile M, Spalletta G, Baldassarre G. Action observation and motor imagery for rehabilitation in Parkinson's disease: A systematic review and an integrative hypothesis. Neuroscience \& Biobehavioral Reviews, 2017;72, 210-222. doi: 10.1016/j.neubiorev.2016.11.005 [PMID: 27865800]

8. Buchignani $B$, Beani $E$, Pomeroy $V$, et al. Action observation training for rehabilitation in brain injuries: a systematic review and meta-analysis. BMC Neurology. 2019;19(1). doi:10.1186/s12883-019-1533-x [PMID: 31881854]

9. Pelosin E, Barella R, Bet C, Magioncalda E, Putzolu M, Di Biasio F, Cerulli C, Casaleggio M, Abbruzzese G, Avanzino L. Effect of group-based rehabilitation combining action observation with physiotherapy on freezing of gait in Parkinson's disease. Neural Plasticity, 2018; pp. 1-7. https://doi.org/10.1155/2018/4897276 [PMID: 29977280]

10. Moher D, Shamseer L, Clarke M, et al. Preferred reporting items for systematic review and meta-analysis protocols (PRISMA-P) 2015 statement. Syst Rev. 2015;4:1 [PMID: 25554246]

11. Iton I, Phillips M, Reardon K, Scarpinella K, Woodcock E, Smith J. Does action observation training reduce freezing of gait among people with Parkinson's disease? A Systematic Review. PROSPERO International Prospective Register of Systematic Reviews (https://www.crd.york.ac.uk/PROSPERO/). 2020, submitted

12. APTA Clinical Practice Guideline Process Manual. Alexandria, VA: American Physical Therapy Association; 2018. Retrieved from http://www.apta.org/EvidenceResearch/EBPTools/CPGs/

13. Centre for Evidence-based Medicine. Oxford Centre for Evidence-based Medicine- Levels of Evidence (March 2009). http://www.cebm.net/oxford-centre-evidence-based-medicine-levels-evidence-march-2009/

14. Shumway-Cook A, Braue $S$, Woollacott M. Predicting the probability for falls in community- dwelling older adults using the timed up \& go test. Physical Therapy. 2000; 80(9): 896-903.

15. Huang SL, Hsieh CL, Wu RM, Tai CH, Lin CH, Lu WS. Minimal detectable change of the timed up and go test and the dynamic gait index in people with Parkinson disease. Physical Therapy. 2011; 91(1), 114-121. doi: 10.2522/ptj.20090126 [PMID: 20947672]

16. Nieuwboer A, Rochester L, Herman T, Vandenberghe W, Emil G, Thomaes T. Reliability of the new freezing of gait questionnaire: agreement between patients with Parkinson's disease and their carers. Gait Posture. 2009;30 (4): 459-463.

17. Giladi N, Shabtai H, Simon ES, Biran S, Tal J, Korczyn AD. Construction of freezing gait questionnaire for patients with parkinsonism. Parkinsonism and Related Disorders. 2000; 6(3), 165-170. doi.org/10.1016/S1353-8020(99)00062-0 [PMID: 10817956] 
18. Hulzinga F, Nieuwboer A, Dijkstra BW, Mancini M, Strouwen C, Bloem BR, Ginis, P. The new freezing of gait questionnaire: unsuitable as an outcome in clinical trials? Movement Disorders. 2020; 7(2), 199-205. doi.org/10.1002/mdc3.12893 [PMID: 32071940]

19. Academy of Neurologic Physical Therapy. Core Measure: 10 Meter Walk Test. https://www.neuropt.org/docs/defaultsource/cpgs/core-outcome-measures/core-measure-10-meter-walk-test-(10mwt)_final.pdf, retrieved June 7. 2021.

20. Lang JT, Kassan TO, Devaney LL, Colon-Semenza C, Joseph MF. Test-retest reliability and minimal detectable change for the 10-meter walk test in older adults with Parkinson's disease. Journal of Geriatric Physical Therapy. 2016;39(4):165-170. doi:10.1519/JPT.0000000000000068 [PMID:26428902]

21. Giorgi G, Ferrarello F, Merlo F, Fumagalli S, Marchionni N, Di Bari M. First-person perspective action observation training in individuals with Parkinson's disease: a consideration-of-concept controlled pilot trial. The Academy of Geriatric Physical Therapy, APTA. 2018; doi: 10.1519/JPT.0000000000000113 [PMID: 27893565]

22. Fahn S, Elton R, Members of the UPDRS Development Committee. In: Fahn S, Marsden CD, Calne DB, Goldstein M, eds. Recent Developments in Parkinson's Disease, Vol 2. Florham Park, NJ. Macmillan Health Care Information 1987.

23. Mezzarobba S, Gassi M, Pellegrin L, Catalarr M, Kruger B, Furtanis G, Manganotti P, Bernardis $P$. Action observation plus sonification. A novel therapeutic protocol for Parkinson's patient with freezing of gait. Frontiers of Neurology. 2018;8, 723. doi: 103389/fneur.2017.00723 [PMID: 29354092]

24. Pelosin E, Avanzino L, Bove M, Stramesi P, Nieuwboer A, Abbruzzese G. Action observation improves freezing of gait in patients with Parkinson's disease. Neurorehabilitation and Neural Repair. 2010;24, (8), 746-752. doi: 10.1177/1545968310368685 [PMID: 20453155]

25. Borenstein M, Hedges LV, Higgins JPT, Rothstein HR. Introduction to Meta-Analysis. 2009. John Wiley \& Sons, Ltd. ISBN:978-0-470-05724-7 [PMID: 26061376]

26. Jackson D, Turner R. Power analysis for random-effects meta-analysis. Res Syn Meth. 2017;8:290-302. doi: 10.1002/jsm.1240 [PMID: 28378395] 